\title{
Using a Novel Variant of Stimulus Fading in the Treatment of Food Refusal and Co-Morbid Challenging Behaviour in a Child with Autism
}

\author{
Ian M Grey ${ }^{1 *}$, Helena Lydon ${ }^{2}$, Olive Healy ${ }^{3}$ and Justin Thomas ${ }^{4}$ \\ ${ }^{1}$ Zayed University, Abu Dhabi, United Arab Emirates \\ ${ }^{2}$ National University of Ireland, Ireland \\ ${ }^{3}$ Trinity College, Ireland \\ ${ }^{4}$ Zayed University, United Arab Emirates
}

Submission: June 26, 2017; Published: July 17, 2017

*Corresponding author: Ian M Grey, Zayed University, Abu Dhabi, United Arab Emirates, Email: ian.grey@zu.ac.ae

\begin{abstract}
Interventions drawn from operant psychology have proven effective in the treatment of food refusal displayed by children with ASD. Multi-component behavioural intervention is typically implemented in such cases and involves escape extinction, stimulus fading and differential reinforcement. However, escape extinction may result in an initial increase in challenging behaviour and may be problematic in cases where such behaviour is severe. The current study implemented a variant of stimulus fading alone in a four year old boy with ASD and a history of food refusal. Parental report indicated that the boy ate a small number of hard textured foods and pureed baby food. Functional assessment indicated that the child was able to chew hard food and shallow pureed food but was unable to eat foods with a combination of hard and soft textures. Stimulus fading was implemented by gradually reducing the latency period between chewing of hard texture and swallowing pureed food. The intervention was implemented without a single occurrence of gagging, vomiting, rejection of food and challenging behaviour. At the end of intervention, the child was eating a variety of age appropriate foods. Clinicians are urged to consider interventions in the treatment of food refusal that may be less aversive for the child to experience prior to the use of escape extinction.
\end{abstract}

Keywords: Food refusal; Autism; Behavioural intervention

\section{Case Report}

It is well documented that children with Autism Spectrum Disorder (ASD) experience higher rates of feeding disorders than typically developing children with some reported prevalence rates being as high as $90 \%$ [1-7]. Food refusal is the most common feeding disorder which is generally linked to food selectivity, whereby the child only eats a narrow range of items, which can place their health and well being at risk [8]. Parents of children with ASD report that feeding difficulties are a particular stressor, and can negatively impact both on caregivers and family functioning $[9,10]$. In particular problem behaviours during mealtimes place additional stress on parents $[9,11]$. To date, behaviourally orientated interventions have a well established research base $[12,13]$ with many successful outcomes resulting from interventions which are matched to the nature of the specific feeding difficulty observed.

Food refusal and food selectivity are amongst the most common types of feeding disorders referred to feeding programs
[14]. Matson et al. [3] reported that 76\% of children with ASD in their sample were found to display food refusal and that the same number preferred food of a certain texture and/or smell. Food texture is a major underlying factor in food selectivity, with Schreck et al. [6] reporting that children with ASD were more likely to accept only foods of low texture. Similarly, Williams et al. [15] found that children's food selectivity was influenced by texture (69\%), appearance $(58 \%)$, taste $(45 \%)$, smell $(36 \%)$, and temperature $(22 \%)$ respectively. The causes of feeding disorders are complex and can range from medical issues such as gastroesophageal issues or cardiopulmonary conditions; neurological conditions; allergies, sensory defects; or environmental factors. These issues may be co-morbid $[14,16]$ or may be as a result of interactions between both biological and environmental factors $[17,18]$. Williams et al. [19] on reviewing 38 intervention studies found that 212 of 218 participants were reported to have a medical aetiology to their food refusal. Therefore, it is hypothesised that if the underlying medical issues 
have been resolved that behavioural interventions can be used to assist in ameliorating the residual feeding problems.

Treatment of food refusal typically involves multicomponent intervention including stimulus fading, differential reinforcement and some form of escape extinction [20]. EE procedures typically take one of two forms

a. Non-removal of the spoon until the child eats the food and

b. Physical guidance which involves physically guiding the child to take a bite [21].

Some authors have claimed that EE is often a necessary component of treatment for food selectivity, but it may be associated with high rates of collateral negative behaviours (e.g. crying or tantrums) particularly during the early stages of implementation [7,22]. Consequently, EE interventions may be aversive for both the child to experience and the caregiver to implement. This poses a particular and unique set of problems for the practitioner in so far as that if behavioural problems surrounding food refusal are sufficiently severe any increase in behaviours associated with EE may increase the risk of harm to the child. Furthermore, caregivers may be unwilling to implement such a procedure as a result. Caregivers may find the stresses sufficiently aversive to discontinue treatment which may inadvertently negatively reinforce such behaviours making subsequent treatment even more difficult.

Despite multi-component intervention for food refusal being frequently recommended and implemented, there remain very few studies examining the relative effects of individual components in isolation and as such it is difficult to identify which components are most beneficial. Owing to the observation that a large number of children with autism demonstrate food refusal, there have been calls for future research to focus on the function of food refusal and selective eating and to link these with particular methods of treatment. Function-based assessments [23-26] can be conducted to extend the work of Munk et al. [27] and Patel et al. [28] to determine how bolus size, food type, texture, flavour, colour, shape, and utensils influence feeding behaviour and food refusal. Such function-based assessments could be used to more accurately prescribe treatments that manipulate the relevant variables (e.g., texture) to expand the variety of foods consumed $[29,30]$.

Stimulus fading is one intervention option [20,22,31-34] which has been used with both liquids and solids to increase bite size, texture and introduce novel foods and liquids. In this procedure, the new stimulus is presented alongside an existing one (e.g. simultaneous presentation) to which an appropriate response had been learnt or is in place. The old stimulus is gradually faded out, and by a process of stimulus attenuation, its frequency or intensity reduced, which allows the new stimulus to gain control of the response (e.g. sequential presentation). Stimulus fading when used for food refusal can occur on several dimensions including texture, type and amount of food/liquid presented. However, whilst beneficial, stimulus fading is likely to be effective only once the particular dimension of stimulus underpinning refusal is correctly identified.

Numerous studies have demonstrated the individual effectiveness of simultaneous $[29,35,36]$ and sequential $[21,37]$ presentation approaches, and comparisons of both procedures [38], in the treatment of food refusal and selectivity. From comparative studies, both method of presentation have been reported to be successful with more rapid change in behaviour reported for simultaneous presentation. However, to date no study has looked at stimulus fading to transition from sequential presentation to simultaneous presentation, and the need for such a procedure to aide in the treatment of texture based feeding selectivity. In this case, we present the case of a young boy who displayed significant food refusal and whose diet was limited to a small number of food stuffs. Functional assessment was used to identify the dimension of food underpinning refusal and a fading procedure was subsequently implemented on its own using existing foodstuffs reliably consumed.

\section{Participant}

Kevin is a four year old boy with autism. He did not have any co-morbid intellectual disability, which is reported in up to $70 \%$ of cases of autism. His intellectual functioning was reported to be at the lower end of the normal range of cognitive functioning (70100). His adaptive behaviour composite score also placed him in the normal range of functioning. He was diagnosed with ASD at 30 months of age. At the time of assessment and intervention he attended a pre-school using an Early Intensive Behavioural Intervention (EIBI) model and had received approximately six months of intervention. He responded well to this model and was reported to display a high rate of acquisition for learning trials and displayed good attention to academic tasks. He learned to request items using sentences, was able to comment on objects, people, and could state preferences using yes and no. His receptive language abilities were not as well developed as his expressive communication skills but he could follow two step instructions, and respond to his name. He was unable to follow prepositions. He lived at home with his mother, father, and older sister. Parents reported satisfaction with his progress and with the model of intervention implemented.

Kevin was referred by his class tutor for assessment due to ongoing problems with food selectivity. This was defined as eating a limited number of preferred foods (i.e., highly pureed food jar of egg custard and rice, rusks, yogurt and potato waffles) and food refusal was defined as refusing to eat any other food when requested to do so or when presented with new or novel foods. Within the pre-school setting Kevin would only eat highly pureed foods (e.g. egg custard and rice). Though Kevin was four years of age, the pureed food he accepted was that typically used for a four month old infant. Kevin displayed significant challenging behaviour when other foods were presented to him. 
In the past this also involved him hitting his head and face off hard objects resulting in the loss of his front teeth. He had also been reported to become sufficiently distressed when presented with new foods that he would emit significant challenging behaviour including throwing himself down stairs in the family home. He was also reported to engage in self-injury as a consequence of food refusal. The occurrence of such behaviours had naturally resulted in his caregivers avoiding situations where new foods were presented to Kevin. Cargivers expressed at the outset they did not wish to see any intervention implemented which would result in challenging behaviour which they found distressing.

\section{Previous Intervention}

Kevin had been previously referred to specialist Speech and Language Therapy services for treatment of food refusal. However, both this and subsequent referral to Occupational Therapy Services had proven unsuccessful. In respect of specialist Speech and Language therapy, no oral pharyngeal dysphasia, neurological or anatomical abnormalities were identified. Behavioural issues were identified and resulted in the application of praise as a potential reinforce to increase appropriate eating. However, this proved unsuccessful. Occupational therapy assessment was implemented and no abnormalities in muscle tone were detected. A possible sensory cause was suggested and coating of the oesophagus with liquid was implemented. This also proved unsuccessful and did not result in an increase in previously rejected foods. He began home tuition at 32 months and commenced specialist pre-school at 45 months which used EIBI model.

\section{Method}

The Questions about Behavioural Function (QABF) [39] was administered with Kevin's care workers in the pre-school and this assessment identified that escape was the primary function of the target behaviour (i.e., food refusal). However, this assessment alone was insufficient to identify what dimension of the food was resulting in food refusal as it not sensitive to identify the particular dimension of food underpinning refusal. The dimensions of behaviourally based food refusal may be taste, texture and physical properties such as colour. Owing to that Kevin ate a small range of different tasting foods, it was decided to assess whether texture of foods was an important variable. To this end, it was decided to systematically alter the texture of a reliably eaten food (i.e., vegetable mash). This was done by presenting Kevin with spoonfuls of purred food with the texture slightly altered by either adding corn flour to increase the consistency of the food and by also by adding in $1 \mathrm{~mm}$ lumps of food taken from the same food but for an older child (i.e., 8 months). The results of this behavioural assessment indicated that any attempt to alter the texture of same food by either method resulted in either immediate ejection or vomiting (Figure 1).

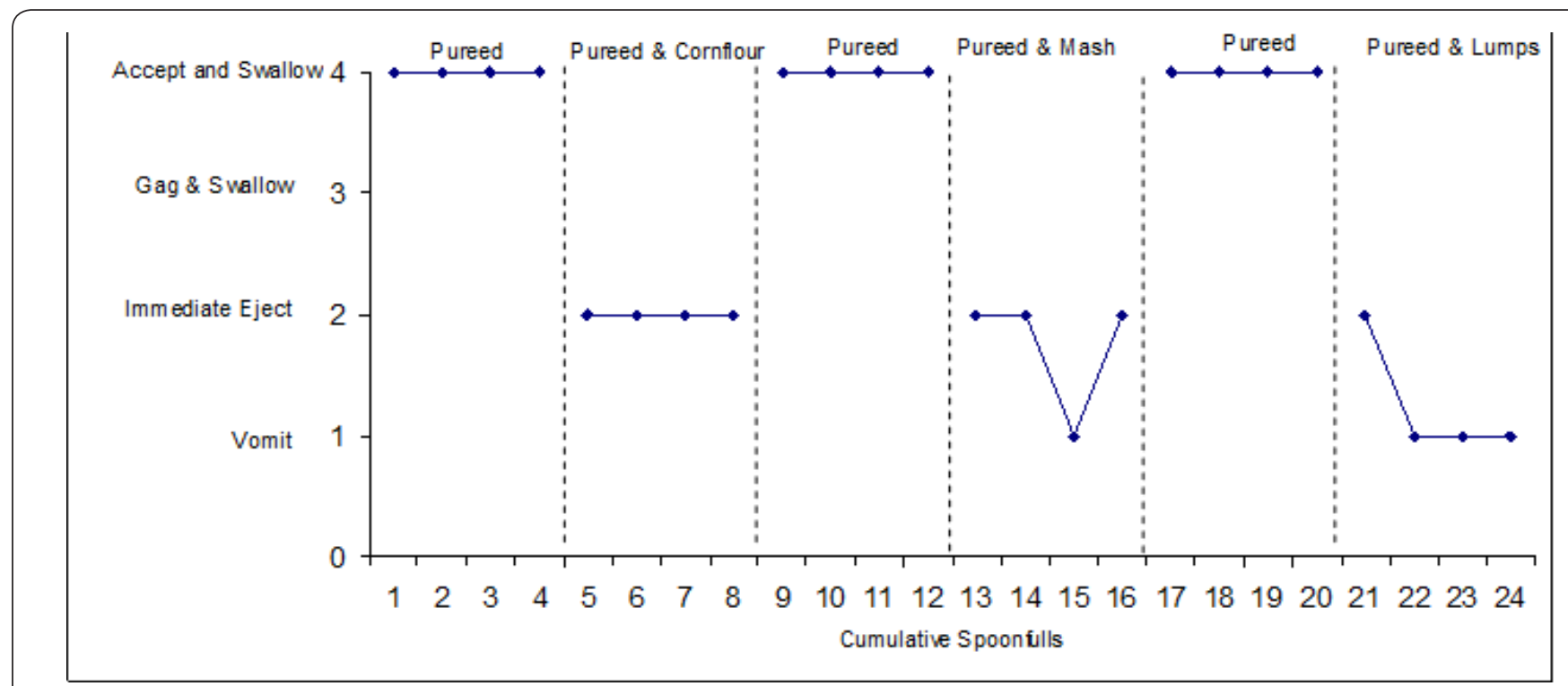

Figure 1: Functional assessment of food refusal.

Initial assessment indicated that food selectivity was maintained by rejection of changing texture within an accepted food. This was established by keeping the taste of the food the same but by altering the texture of previously accepted foods. However, this assessment indicated that stimulus fading across texture was not going to be effective by altering the consistency of the food as even slight changes in texture and the inclusion of two $1 \mathrm{~mm}$ lumps of food in a spoonful of pureed food were sufficient to result in either immediate ejection of the food or vomiting. Owing to the severity of challenging behaviours that had occurred in the past, escape extinction was not considered a viable treatment component. However, it was clear that Kevin did not reject all textures as he reliably ate rusks which have a very hard texture. As a result of this consideration, it was conceptualised that Kevin had the ability to chew and accepted different textures of food. However, the difficulty appeared to be 
of one of stimulus control in so far as that Kevin swallowed foods that had a very soft texture (e.g., pureed food) and chewed foods that had a very hard texture (e.g., rusks) but was unable to accept foods that had a combination of both textures [40].

\section{Intervention}

Fading to increase texture from very soft to very hard was unlikely to be effective from the data produced by the functional assessment conducted. As a result, a reverse fading procedure was developed and tracked using observation data across four categories of responses
a. Accept and swallow.
b. Gag and swallow.
c. Immediate ejection and
d. Vomiting.

The adapted fading procedure involved establishing chewing with rusks first and gradually adding in pureed food following chewing. This involved three phases. In phase 1 (Figure2), the latency of the Rusk naturally turning to puree after being placed in the mouth was established. This was determined to be 16 seconds and after this period of time had elapsed, Kevin was presented with a spoon of normal pureed food. The latency period between presentation of the Rusk and the subsequent presentation of the pureed food was systematically reduced over successive sessions until the two were presented simultaneously. In phase 2 (Figure 3), the Rusk and pureed food were presented simultaneously but beginning with a small bite sized Rusk being presented on a normal spoon covered in pureed food. The presentation of Rusk and pureed food then alternated between the Rusk being on top of or under the pureed food. In phase 3 (Figure 4), the amount of Rusk presented with pureed food was increased. In the fourth and final phase (Figure 5), lumps of food of increasing size from a normal jar of the same food (i.e., 12 months) were presented with a Rusk culminating with presentation of food from a normal jar of un pureed food. A final generalisation test was also conducted and Kevin was eating non-pureed foods consistently and was able to eat a variety of other age appropriate foods (e.g., pizza slices).

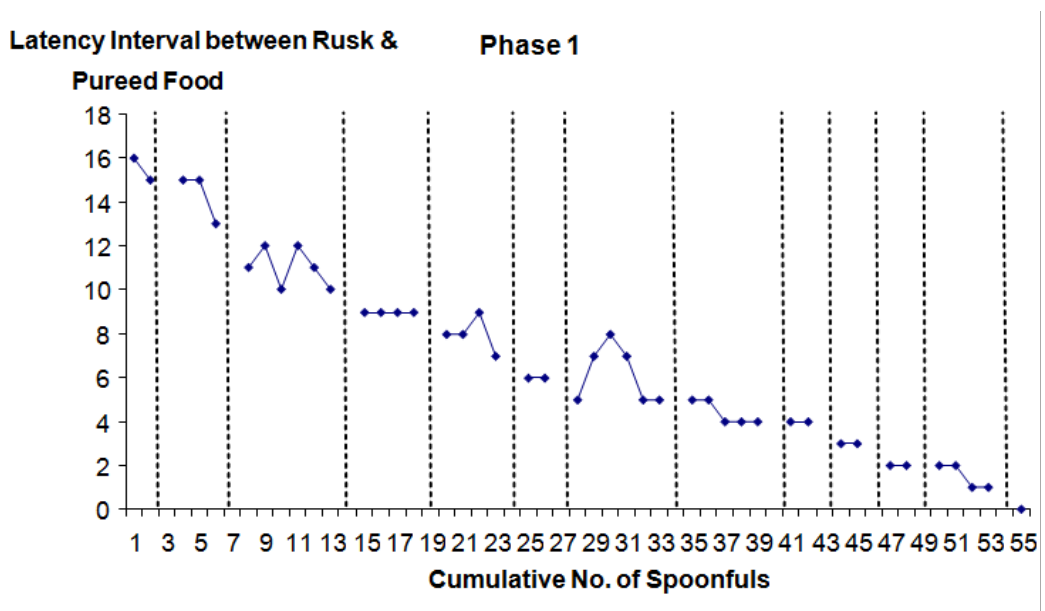

Figure 2: Latency of interval between rusk and pureed food presentation.

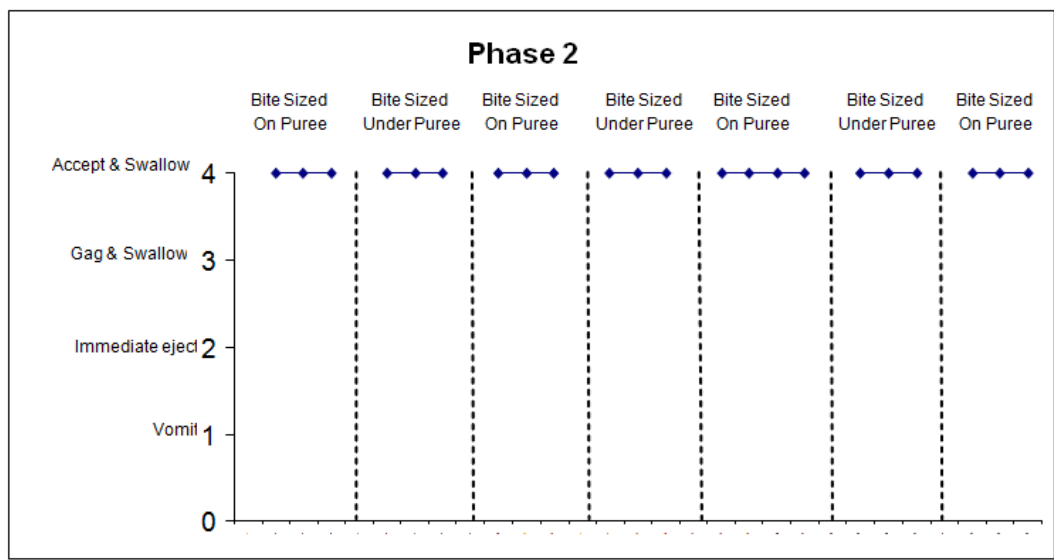

Figure 3: Simultaneous presentation of rusk and pureed food. 


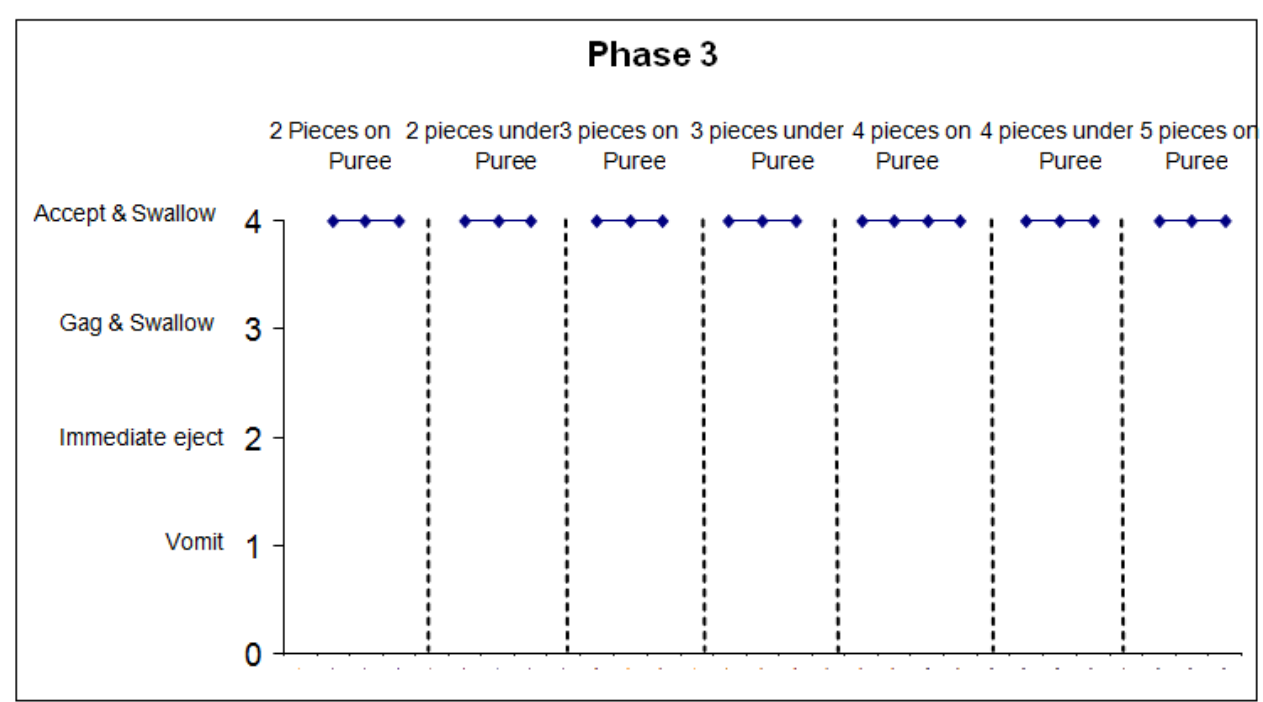

Figure 4: Simultaneous presentation of increasing rusk size and pureed food.

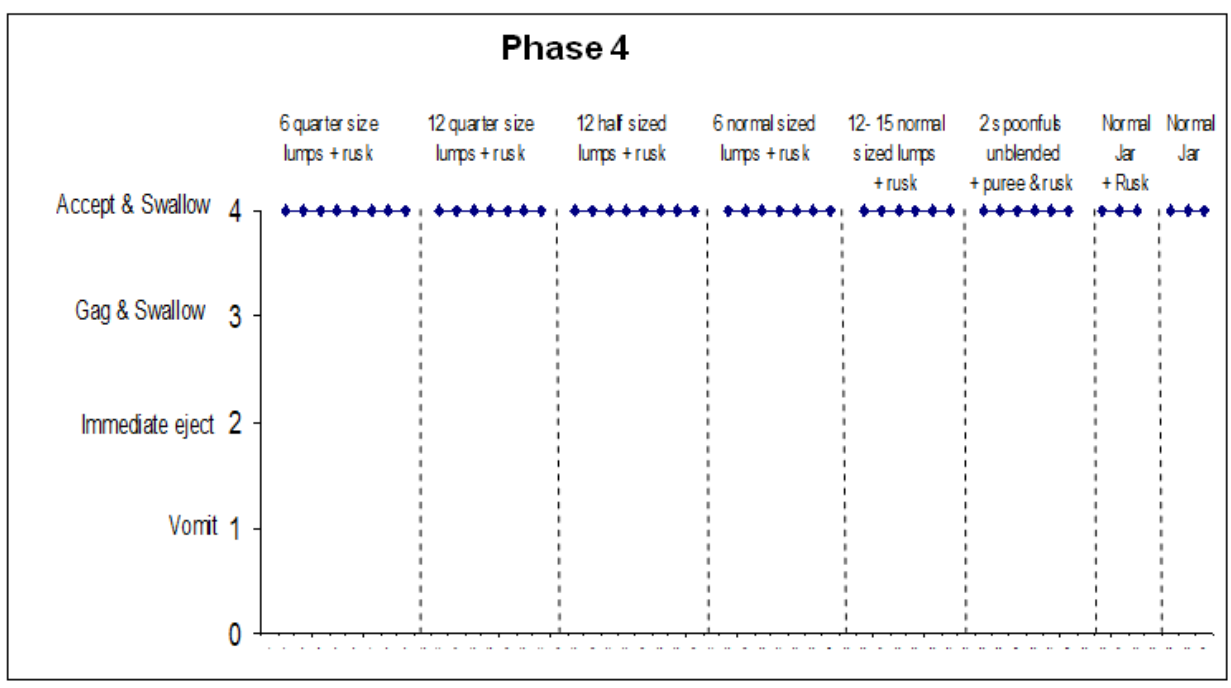

Figure5: Presentation of rusk plus increasing size of lumps of normal food.

Because Kevin attended a busy EIBI class for children with autism and owing to the typical focus of intervention on preacademic and academic skills, generally only a limited time was available for lunch breaks etc. To facilitate effective intervention, increased time had to be devoted to correct presentation of intervention phases and collateral preparation of materials which resulted in decreased access to intervention in other areas for a relatively short period of time. The intervention also required that a tutor was available to implement all phases correctly and consistently which can result in a cost element for schools in general but was not an issue in the current school. It was considered important to avoid any gaps in the intervention sequence which took place on consecutive days over a three week period. A final complicating factor revolved around the issue of generalisation and consistency with the home environment.
Inconsistency of application of behavioural interventions is a known mitigating variable with respect to their effectiveness. In the current case, parents were informed of the intervention from the outset and it was decided to implement the intervention in the school environment alone until its effectiveness had been demonstrated. Kevin's parents had experienced previous failures of intervention in the past and as such it was considered premature to implement the intervention simultaneously in both locations. Once efficacy of the intervention was demonstrated in the classroom setting, parents were then willing to implement it in the home setting.

Kevin's mother was contacted at various intervals over a six month period following intervention. She reported that the family no longer presented pureed food of any particular 
flavour to Kevin and that he was eating normal foods presented in a normal fashion to him and with other family members. His mother also reported there was a substantial reduction in tantrums and other negative behaviours to a near zero rate and that he was much more compliant with instruction at meal-times.

\section{Discussion}

The primary treatment implication of the case is that food refusal can be successfully treated by use of stimulus fading alone rather than by multi-component intervention including extinction procedures. While multi-component treatment has been reported to be effective, it may not always be practical particularly in cases where the use of escape extinction is likely to result in severe challenging behaviours. Furthermore, escape extinction is an aversive procedure and with all aversive procedures they should only be implemented as a last resort. This is particularly pertinent in light of the fact that clinicians are ethically bound to adopt least restrictive procedures first. The current study illustrates that at least in at least some cases, stimulus fading without escape extinction can be effective. The intervention presented here was conducted in a manner that did not result in an aversive experience for the child. Throughout the intervention, Kevin did not emit challenging behaviour and did not engage in gagging, rejection of food or vomiting.

Based upon the findings in the current case study, clinicians and students are recommended to implement modified functional assessment methodology to identify from the outset the specific idiosyncratic features of food presentation that result in food refusal [29]. The use of such methodology allows for a more precise tailoring of subsequent intervention. More specifically, it can allow for a selection of specific individual components rather than an 'off the shelf' multi-component intervention that may take longer to implement, may be associated with aversive components and may not be any more differentially effective. The need for comparisons of the effectiveness of various individual procedures involved in the treatment of food refusal has been made before and the work presented here represents an answering of that call [8]. Clinicians and students are encouraged to examine instances of food refusal on a case by case basis and to be creative in the solutions to this problem whilst having a good knowledge of behavioural principles by examining how they can modify procedures to produce idiosyncratic interventions that work with minimal intrusiveness.

Critical to the success of behavioural intervention for food refusal is access to trained individuals who can implement and monitor treatment plans as they are being implemented. Despite food refusal being well established in Kevin's case, it took a number of years before he was referred for behavioural intervention. Furthermore, he had been previously referred to both Speech and Language Therapy and Occupational Therapy though with no obvious success. The issue that arises from this observation relates to timely access to effective intervention for children with autism and food refusal before these behaviours become more established or before negative health and nutritional consequences ensue. In many countries, access to behavioural intervention is extremely limited particularly in preschool and primary school locations. It would appear that in some cases, access to care is on the basis of access to multi-disciplinary structures rather than access to evidence based interventions. Whilst clinical psychology services are typically included in these structures, the issue of clinical psychologists having relevant and sufficient training in behavioural psychology is an issue for assessment and effective intervention. Furthermore, there is a debate concerning the relative value of questionnaire based methods of assessment to capture the necessary dimensions of food refusal to enable effective intervention [41]. Function based assessments based on direct observation are time consuming and what remains lacking to date are studies regarding the convergent validity of questionnaire based assessment versus assessment based upon direct observation. Such studies would be beneficial to future practitioners and may result in less time being devoted to functional assessment methodologies.

\section{References}

1. Bandini LG, Anderson SE, Curtin C, Cermak S, Evans EW, et al. (2010). Food selectivity in children with autism spectrum disorders and typically developing children. J Pediatr 157(2): 259-264.

2. DeMeyer MK (1979) Parents and children in autism. John Wiley, New York, USA.

3. Fodstad JC, Matson JL (2008) A comparison of feeding and mealtime problems in adults with intellectual disabilities with and without autism. Journal of Developmental and Physical Disabilities 20(6): 541550 .

4. Ledford JR, Gast DL (2006) Feeding problems in children with autism spectrum disorders: A review. Focus on Autism and Other Developmental Disabilities 21(3): 153-166.

5. Schreck KA, Williams K (2006) Food preferences and factors influencing food selectivity for children with autism spectrum disorders. Res Dev Disabil 27(4): 353-363.

6. Schreck KA, Williams K, Smith AF (2004) A comparison of eating behaviors between children with and without autism. J Autism Dev Disord 34(4): 433-438.

7. Seiverling L, Kokitus A, Williams K (2012) A clinical demonstration of a treatment package for food selectivity. The Behavior Analyst Today 13(2): 11-16.

8. Kozlowski AM, Matson JL, Belva B, Rieske R (2012) Feeding and sleep difficulties in toddlers with autism spectrum disorders. Research In Autism Spectrum Disorders 6(1): 385-390.

9. Kodak T, Piazza CC (2008) Assessment and behavioral treatment of feeding and sleeping disorders in Children with autism spectrum disorders. Child Adolesc Psychiatr Clin N Am 17(4): 887-905.

10. Martin C, Southall A, Shea E, Marr A (2008) The importance of multifaceted approach in the assessment and treatment of childhod feeding disorders. Clinical Case Studies 7(2): 79-99.

11. Leung C, Lau J, Chan G, Lau B, Chui M (2010) Development and validation of a questionnaire to measure the service needs of families with children with developmental disabilities. Res Dev Disabil 31(3): 664-671.

12. Bachmeyer MH (2009) Treatment of selective and inadequate food intake in children: A review and practical guide. Behav Anal Pract 2(1): 43-50.

13. Volkert VM, Vaz PC (2010) Recent studies of feeding problems in 
children with autism. J Appl Behav Anal 43(1): 155-159.

14. Field D, Garland M, Williams K (2003) Correlates of specific childhood feeding problems. J Paediatr Child Health 39(4): 299-304.

15. Williams KE, Gibbons BG, Schreck KA (2005) Comparing selective eaters with and without develop-mental disabilities. Journal of Developmental and Physical Disabilities 17: 299-309.

16. Rudolph CD, Link DT (2002) Feeding disorders in infants and children. Pediatr Clin North Am 49(1): 97-112.

17. Milnes SM, Piazza CC, Carroll T (2013) Assessment and Treatment of Pediatric Feeding Disorders. Child Nutrition.

18. Rommel N, De Meyer AM, Feenstra L, Veereman-Wauters G (2003) The complexity of feeding problems in 700 infants and young children presenting to a tertiary care institution. J Pediatr Gastroenterol Nutr 37(1): 75-84.

19. Williams KE, Field DG, Seiverling L (2010) Food refusal in children: A review of the literature. Research in Developmental Disabilities 31(3): 625-633.

20. Freeman KA, Piazza CC (1998) Combining stimulus fading, reinforcement, and extinction to treat food refusal. J Appl Behav Anal 31(4): 691-694.

21. Pizzo B, Coyle M, Seiverling L, Williams K (2012) Plate A-Plate B: Use of sequential presentation in the treatment of food selectivity. Behavioral Interventions 27: 175-184.

22. Roth MP, Williams KE, Paul CM (2010) Treating food and liquid refusal in an adolescent with asperger's disorder. Clinical Case Studies 9(4): 260-272.

23. Huete JM, Kurtz PF (2010) Therapist effects on functional assessment outcomes with young children. Research in Developmental Disabilities 31(3): 804-810

24. Kozlowski AM, Matson JL, Fodstad JC, Moree BN (2011) Feeding therapy in a child with autistic disorder: Sequential food presentation. Clinical Case Studies 10(3): 236-246.

25. Weeden M, Mahoney A, Poling A (2010) Self-injurious behaviour and functional analysis: Where are the descriptions of participant protections? Res Dev Disabil 31(2): 299-303.

26. Volkert VM, Petula C (2010) Recent studies on feeding problems in children with autism. Journal of Applied Behaviour Analysis 43(1): 155-159.

27. Munk DD, Repp AC (1994) Behavioral assessment of feeding problems of individuals with severe disabilities. J Appl Behav Anal 27(2): 241250 .

28. Patel MR, Piazza CC, Layer SA, Coleman R, Swartzwelder DM (2005)

This work is licensed under Creative Commons Attribution 4.0 Licens DOI: 10.19080/GJIDD.2017.01.555572
A Systematic Evaluation of Food Textures to Decrease Packing and Increase Oral Intake in Children with Pediatric Feed Disorders. J Appl Behav Anal 38(1): 89-100.

29. Ahearn WH (2003) Using simultaneous presentation to increase vegetable consumption in a mildly selective child with autism. J Appl Behav Anal 36(3): 361-365.

30. Seiverling LJ, Williams KE, Ward-Horner J, Sturmey P (2011) Interventions to treat feeding problems in children with autism spectrum disorders: A comprehensive review. International handbook of autism and pervasive developmental disorders, pp. 491-508.

31. Bachmeyer MH, Gulotta CS, Piazza CC (2013) Liquid to baby food fading in the treatment of food refusal. Behavioral Interventions 28(4): 281-298.

32. Luiselli JK (2000) Cueing, demand fading, and positive reinforcement to establish self-feeding and oral consumption in a child with chronic food refusal. Behav Modif 24(3): 348-358.

33. Luiselli JK, Gleason DJ (1987) Combining sensory reinforcement and texture fading procedures to overcome chronic food refusal. J Behav Ther Exp Psychiatry 18(2): 149-155.

34. Paul C, Williams KE, Riegel K, Gibbons B (2007) Combining repeated taste exposure and escape prevention: An intervention for the treatment of extreme food selectivity. Appetite 49(3): 708-711.

35. Kern L, Marder TJ (1996) A comparison of simultaneous and delayed reinforcement as treatments for food selectivity. J Appl Behav Anal 29(2): 243-246.

36. Luiselli JK, Ricciardi JN, Gilligan D (2005) Liquid fading to establish milk consumption by a child with autism. Behavioural Interventions 20: 155-163.

37. VanDalen KH, Penrod B (2010) A comparison of simultaneous versus sequential presentation of novel foods in the treatment of food selectivity. Behavioural Interventions 25(3): 191-206.

38. Matson JL, Fodstad JC, Dempsey T (2009) The relationship of children's feeding problems to core symptoms of autism and PDD-NOS. Research In Autism Spectrum Disorders 3(3): 759-766.

39. Paclawskyj TR, Matson JL, Rush KS, Smalls Y, Vollmer TR (2000) Questions about Behavioral Function (QABF): A behavioral checklist for functional assessment of aberrant behavior. Res Dev Disabil 21(3): 223-229.

40. Kadey HJ, Roane HS, Diaz JC, Merrow JM (2013) An evaluation of chewing and swallowing for a child diagnosed with autism. Journal of Developmental And Physical Disabilities 25(3): 343-354.

41. Ahearn WH, Castine T, Nault K, Green G (2001) An assessment of food acceptance in children with autism or pervasive developmental disorder-not otherwise specified. J Autism Dev Disord 31(5): 505-511.

\section{Your next submission with Juniper Publishers will reach you the below assets}

- Quality Editorial service

- Swift Peer Review

- Reprints availability

- E-prints Service

- Manuscript Podcast for convenient understanding

- Global attainment for your research

- Manuscript accessibility in different formats

( Pdf, E-pub, Full Text, Audio)

- Unceasing customer service

Track the below URL for one-step submission https://juniperpublishers.com/online-submission.php 